\title{
Normal McCollough effect in Alzheimer's disease and global amnesia
}

\author{
ROBERT L. SAVOY \\ Rowland Institute for Science, Cambridge, Massachusetts \\ and \\ JOHN D. E. GABRIELI \\ Massachusetts Institute of Technology, Cambridge, Massachusetts
}

\begin{abstract}
The McCollough effect (ME), a long-lasting, pattern-contingent aftereffect in normal human vision, was examined in persons with known deficits in memory. We induced MEs in 11 subjects, 5 patients with various severities of Alzheimer's disease (AD), H.M. (a patient who has global amnesia due to bilateral medial temporal lobectomy and who has been studied for 35 years since his operation), and 5 control subjects. H.M. and the AD patients showed MEs of strength and duration comparable to those of the control subjects. These results demonstrate a dissociation between learning mechanisms that mediate recall and recognition versus mechanisms that mediate the ME. Furthermore, knowledge about the sites of neuropathology in H.M. and in AD are consistent with other sources of evidence implicating early visual areas, especially V1, as a critical locus of the ME.
\end{abstract}

The McCollough effect (ME) (McCollough, 1965) is a long-lasting, pattern-contingent color aftereffect in human vision. "Pattern-contingent" refers to the fact that the color aftereffect is observed only on test patterns that have spatial orientations and spatial frequencies similar to those of the adapting pattern. "Long-lasting"' refers to the fact that exposure to the adapting patterns for only $5 \mathrm{~min}$ generates aftereffects that are easily measurable $1 \mathrm{~h}$ later. With longer adaptations (such as $15 \mathrm{~min}$ ), measurable MEs have been reported days and even weeks later (Jones \& Holding, 1975).

There has been considerable interest and debate in classifying the ME in regard to traditional categories of learning and memory (see, e.g., Murch, 1976; Savoy, 1984a, 1984b; Skowbo, 1984; Skowbo, Timney, Gentry, \& Morant, 1975), and there has been some speculation and theoretical work on the possible underlying neural systems. Most of the modeling has involved the "fatigue" or "adaptation" of individual neurons (or theoretical neurons). Proposed physiological sites for such neurons include the retina, the lateral geniculate nucleus, and

This research was supported by grants MH24433, AG06605, P500AG5134, RR00088, IIRG-89-081, and 1P50NS26985, by a grant from the Alzheimer's Disease Research Fund of the Illinois Department of Public Health, and by the Rowland Insititute for Science. We would like to express our gratitude to Suzanne Corkin and John H. Growdon for referring patients and control subjects; to Jeremy Wolfe for early discussions; and to Jennifer Cohen and Joy Yucaitis for scheduling and transporting subjects. We would also like to thank Dr. Corkin for helpful discussions of the manuscript. John D. E. Gabrieli is now at the Department of Psychology, Northwestern University, Evanston, IL 60208. Requests for reprints may be sent to Robert L. Savoy, Rowland Institute for Science, 100 Cambridge Parkway, Cambridge, MA 02142. the visual cortex (see, e.g., Harris \& Gibson, 1968; Krüger, 1979; Michael, 1978; Montalvo, 1976; Stromeyer \& Dawson, 1978). Other speculation has required the interaction of more than one class of neuron to account for the various aspects of the ME (see, e.g, Savoy, 1984a, 1984b). Despite this range of speculation, there is as yet no direct evidence linking the ME to particular neural substrates.

Experimental studies of memory-disordered patients with brain lesions have provided considerable evidence about the neural bases of various forms of behavioral plasticity (for summaries, see Gabrieli, in press, and Squire, 1986). Despite their memory disorders, such patients exhibit preserved learning capacities in certain domains. The documentation of preserved learning in a patient with memory dysfunction provides strong evidence in favor of the separable neural bases of the preserved and impaired learning capacities. Further, to the extent that the locus of lesion is understood in the patient, it becomes possible to identify the putative neural system that mediates the form of plasticity under investigation. The present study examines the status of the ME in patients with salient memory disorders due to global amnesia or Alzheimer's disease (AD).

Patients with global amnesia have a relatively circumscribed deficit in the ability to recall and recognize materials or events experienced subsequent to the onset of their amnesia. Amnesic patients retain relatively normal perceptual, motoric, and cognitive capacities. These patients have lesions of limbic structures located in the medial temporal lobes or diencephalon (see, e.g., Scoville \& Milner, 1957; Victor, Adams, \& Collins, 1971; ZolaMorgan, Squire, \& Amaral, 1986). The locus of lesion 
is particularly well understood in one patient, H.M., whose lesion was made surgically in an attempt to alleviate his intractable epilepsy. The bilateral removal included the prepyriform gyrus, uncus, amygdala, hippocampus, and parahippocampal gyrus and extended an estimated $8 \mathrm{~cm}$ back from the tips of the temporal lobes (Scoville, Dunsmore, Liberson, Henry, \& Pepe, 1953). Since that operation in 1953, H.M. has had a profound and pervasive global amnesia (Corkin, 1984; Scoville \& Milner, 1957).

Patients with dementia due to $\mathrm{AD}$ also have a memory disorder, but neither their memory disorder nor their pattern of neuropathology is circumscribed as in the case of H.M. Such patients have widespread impairments in language, reasoning, and other aspects of cognition (Adams \& Victor, 1985). Although the neuropathology in AD is multifocal in nature (involving cortical as well as subcortical regions), it does not affect all areas uniformly. As in the case of global amnesia, AD patients consistently have severe lesions of limbic structures, including the hippocampal formation (see, e.g., Hyman, Van Hoesen, Damasio, \& Barnes, 1984). According to postmortem neuropathological and in vivo metabolic studies, $A D$ patients also have damage to neocortical regions, including the temporal, parietal, and frontal lobes. Primary motor and sensory areas (including the visual cortex) are relatively spared, especially in the early phase of the disease (see, e.g., Brun \& Englund, 1981; Frackowiak, Pozzilli, Legg, Du Boulay, Marshall, Lenzi, \& Jones, 1981; Johnson, Holman, Mueller, Rosen, English, Nagel, \& Growdon, 1988; Lewis, Campbell, Terry, \& Morrison, 1987).

Some forms of learning are preserved despite amnesia or dementia of the Alzheimer's type. H.M. and AD patients have deficits in what has been termed declarative (Cohen \& Squire, 1980), explicit (Graf \& Schacter, 1985), or event-fact memory (Gabrieli, in press). Memory deficits of this sort are measured on tests of new learning in which an event occurs and memory for that event is subsequently measured on tests of recall or recognition. Despite their impairments in these tasks, H.M. and AD patients have shown nearly or entirely normal magnitudes of learning on a variety of tasks that have been described as tapping procedural (Cohen \& Squire, 1980) or implicit memory (Graf \& Schacter, 1985). For example, H.M. and AD patients have shown substantial learning on sensorimotor tasks such as mirror tracing and rotary pursuit (Corkin, 1968; Eslinger \& Damasio, 1986). Other sorts of learning are preserved in H.M. and impaired in AD (Gabrieli et al., 1991).

It would be incorrect, however, to conclude that relatively primitive forms of memory are preserved uniformly in AD. For example, two studies have found substantial impairments in AD patients' ability to acquire classical eyeblink conditioning (Solomon, Levine, Bein, \& Pendlebury, 1989; Woodruff-Pak, Finkbiner, \& Katz, 1989). Conversely, AD patients have shown normal levels of a sensorimotor aftereffect, weight biasing (Heindel, Salmon, \& Butters, 1989).
The present study examined the magnitude and duration of the ME in H.M. and in AD patients for delays $(5,25$, and $60 \mathrm{~min})$ at which the recall and recognition impairments of the patients are manifest (see, e.g., Corkin, 1982; Gabrieli, in press; Scoville \& Milner, 1957). Intact MEs in any of these patients, therefore, would suggest that the ME is mediated by neural systems that are relatively intact. Such a finding would have strong implications about the plausible neural site of the ME.

\section{METHOD}

\section{Subjects}

One subject was the amnesic patient H.M. (described previously). The remaining subjects were 5 patients with Alzheimer's disease and 5 control subjects.

The AD patients were mildly to moderately demented and were consecutive ${ }^{1}$ cases who were willing to volunteer for the study. The five patients met the NINCDS and NIA research criteria for the diagnosis of probable AD (Khachaturian, 1985; McKahn, Drachman, Folstein, Katzman, Price, \& Stadlan, 1984). Table 1 shows the ages and levels of education for all subjects and the Blessed Dementia Scale (BDS) scores of the AD patients. The mean ages were 61 years for the AD patients and 57 years for the controls.

The control subjects were spouses of patients and paid volunteers who had been screened to rule out dementia (i.e., they had BDS scores of less than 3 ).

\section{Apparatus}

Stimuli were presented on a Mitsubishi color monitor, driven by an International Imaging System $70 \mathrm{~F}$ image processor with 30 bits of color resolution, which is higher color resolution than is necessary for this sort of work. Spatial resolution was $512 \times 512$ pixels in an $11 \times 11$ in. $(30 \times 30 \mathrm{~cm})$ display area on a 19 -in. $(48-\mathrm{cm})$ television monitor, viewed from approximately $28 \mathrm{in}$. $(71 \mathrm{~cm})$.

The adapting patterns were green (pure green television gun, chromaticity coordinates of $x=.29, y=.60$ ) and magenta (pure red + blue television guns, chromaticity coordinates $x=.615, y=.35$ and $x=.23, y=.24$, respectively). The luminance of the light bars in the adapting patterns was $52 \mathrm{~cd} / \mathrm{m}^{2}$. The luminance of the light stripes in the test pattern was $38 \mathrm{~cd} / \mathrm{m}^{2}$, with a neutral chromaticity of $x=.27, y=.30$. Adjusting the test pattern colors

Table 1

Subject Characteristics

\begin{tabular}{|c|c|c|c|}
\hline Subjects & Age & $\begin{array}{l}\text { Years of } \\
\text { Education }\end{array}$ & $\begin{array}{c}\text { BDS } \\
\text { Scores }\end{array}$ \\
\hline $\begin{array}{r}\text { AD Patients: } 1 \\
2 \\
3 \\
4 \\
5\end{array}$ & $\begin{array}{l}69 \\
52 \\
57 \\
69 \\
60\end{array}$ & $\begin{array}{l}19 \\
12 \\
16 \\
12 \\
12\end{array}$ & $\begin{array}{l}25 \\
14 \\
18.5 \\
22 \\
9\end{array}$ \\
\hline 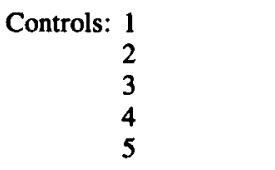 & $\begin{array}{l}58 \\
63 \\
52 \\
57 \\
55\end{array}$ & $\begin{array}{l}12 \\
12 \\
14 \\
12 \\
16\end{array}$ & \\
\hline Amnesic Patient H.M. & 62 & 12 & \\
\hline
\end{tabular}

Note-BDS = Blessed Dementia Scale, AD = Alzheimer's disease. 
resulted in movement along a line connecting the pure green and pure magenta chromaticity coordinates. More information about this apparatus is available in Savoy (1984b, 1986).

\section{Procedure}

The ME was generated and measured quantitatively in three phases: a baseline phase, an adaptation phase, and a test phase consisting of measurements taken at 5,25 , and $60 \mathrm{~min}$ after the end of the adaptation phase.

The adapting patterns consisted of a green-and-black square-wave grating with the bars oriented at $+45^{\circ}$ and a magenta-and-black square-wave grating with bars oriented at $-45^{\circ}$. Each grating was circular in outline, subtended $22^{\circ}$, and had a nominal spatial frequency of 2 cycles per degree. The adapting patterns were viewed binocularly, with no head restraint; subjects were reminded to sit straight in their chairs.

The subjects looked at the television monitor, which presented a test pattern such as the one shown in Figure 1, except that instead of being a neutral (colorless) pattern, it had a small, random amount of color added. The background color was a fixed-intensity gray. The black bars were fixed. The subjects controlled the color of the light bars along a constant luminance magenta-green axis by moving a trackball. All the light bars along one diagonal changed together. As those bars became more green (or magenta), the orthogonal light bars became more magenta (or green). The subjects' task was to make the test pattern appear neutral.
Subjects who were capable of making their own trackball adjustments did so directly. The ability of AD patients to make their own settings was not obviously related to the severity of their disease. In particular, the most demented $A D$ patient tested (as indicated by the highest BDS score) was a very good psychophysical subject, both in terms of his ability to make the settings and in the normal degree of variability in those settings.

For subjects who had difficulty using the trackball, the experimenter made adjustments according to verbal responses from the subjects. The experimenter did not look at the test pattern in these cases. Some of the AD patients could respond to a simple color comparison question, such as, "Which bars are redder, these [assistant points], or these?"' For such subjects, the experimenter would adjust the trackball until the subject responded that there was no discernible difference. Two AD subjects did not give clear responses to the color comparison question ("Which is redder?"), so a simpler question was devised, "Is there any color in this [the test] pattern?" All subjects could answer this question. However, because there was no color direction information given with such a procedure, the experimenter could not actually find a null setting. Instead, the test pattern was initially set with lots of color, and the colors were gradually desaturated until the subject reported no color. This was done from both the "reddish" and "greenish" starting directions, and the average of those settings was taken to be the subject's neutral setting. This yielded mean neutral settings, but there was no obvious way to measure standard deviation for

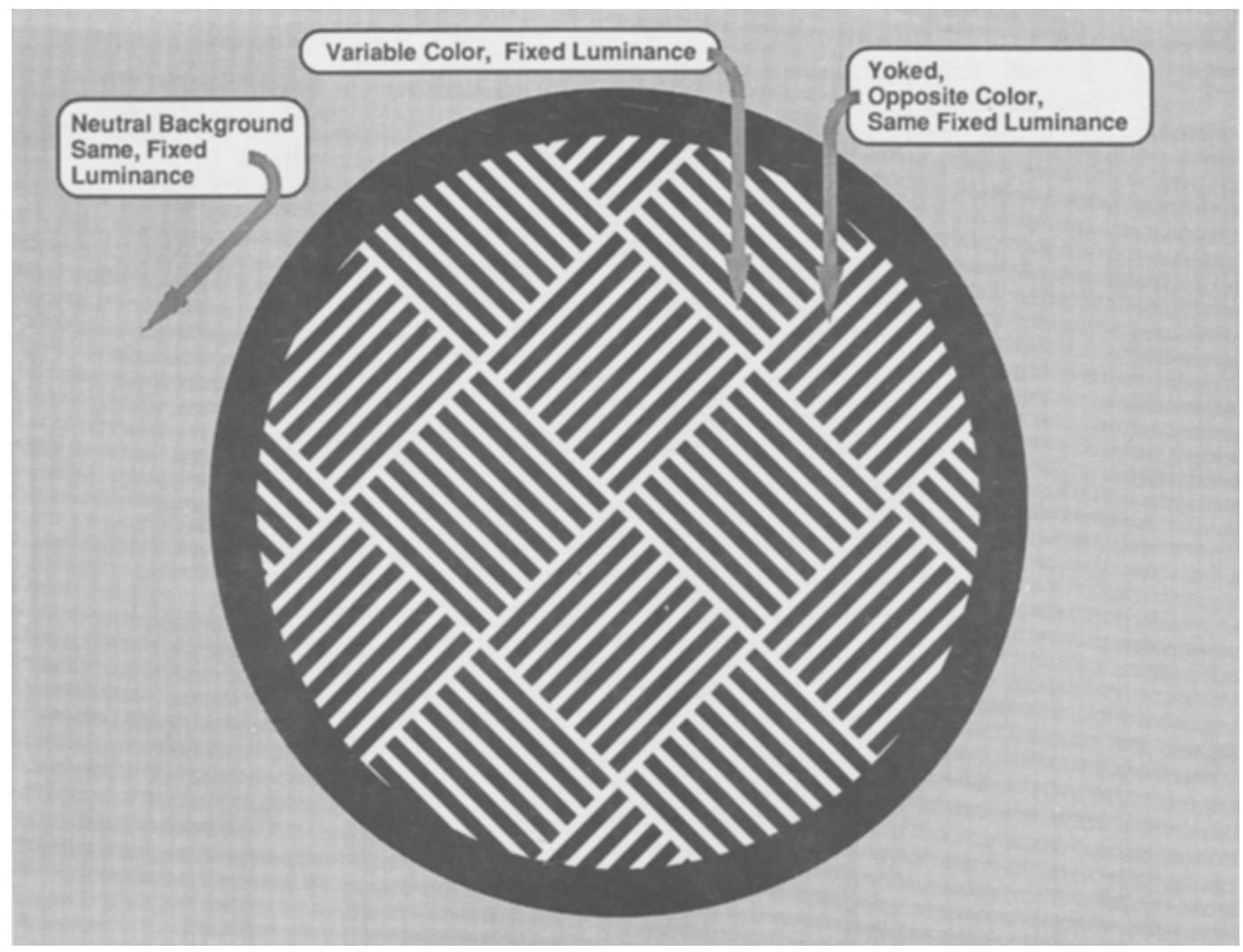

Figure 1. The standard test pattern: The background was a neutral gray, of fixed luminance and color. The dark bars were black. The bars shown in the figure as white were of variable color but fixed luminance. As the subject (or experimenter) moved the trackball, all the light bars of one orientation became greener (or more magenta) while all the light bars of the opposite orientation moved in the complementary color direction. The subject's task was to make the bars appear neutral (colorless). 
this procedure. These procedures were also used a few times with normal controls and $A D$ patients who could make their own adjustments, just to confirm that both procedures yielded comparable measures.

Baseline phase. The subjects' task was to make the entire test display appear neutral (colorless). Subjects were also shown a photographic test pattern that was objectively neutral (colorless) and were asked whether any colors were seen. No subjects reported seeing color in the photographic test pattern prior to adaptation.

Adaptation phase. Subjects viewed the two adapting patterns for a total of $5 \mathrm{~min}$ : 60 presentations, each lasting $5 \mathrm{sec}$, with the two stimuli alternating.

Testing phase. Subsequent to the $5 \mathrm{~min}$ of adaptation, subjects waited an additional $5 \mathrm{~min}$ before looking at the television test pattern and adjusting it to apparent neutral (as they had done in the baseline phase). The 5-min wait at the end of adaptation was included to avoid the steepest part of the decay-versus-time curve after ME adaptation. Subjects were also shown the (neutral) photographic test pattern and asked whether any color was seen. This test was repeated $25 \mathrm{~min}$ and $60 \mathrm{~min}$ after the end of the adaptation phase.

H.M.'s memory for the adaptation phase was assessed by tests of recall and multiple-choice recognition for such information as the color of the adapting patterns. The memory of the AD patients was assessed informally; when a patient obviously recalled the situation, testing of memory was not done, but when there appeared to be trouble remembering the test situation, a protocol similar to that used with H.M. was followed.

\section{RESULTS}

H.M. and the AD patients exhibited MEs of a magnitude and duration indistinguishable from those of the normal control subjects.

The results are shown in Figures 2-4. The ordinate is a measure of ME strength; it is the distance, in $L, \mathrm{u}^{*}, \mathrm{v}^{*}$ uniform color space, between the colors of the differently oriented bars in the test pattern that the subjects chose to look neutral. Since, by design, the luminance (L) was constrained to be fixed, the distance represents a chroma + purity distance (hue + saturation) with no luminance distance component.

The first plots (Figure 2) are for two individual patients, H.M. and one of the AD patients. Although these two patients had the most striking memory impairments, their psychophysical performance was especially consistent.

Figure 3 shows the data for all 11 subjects. The mean settings and standard deviations are shown as they were in Figure 2, except that for some subjects only the mean is shown (for reasons explained in the Procedure section). Note that the baseline setting for all subjects was near zero. Note, too, that all subjects show a clear ME and that it decreased gradually over the course of $1 \mathrm{~h}$. There is no apparent difference in the time course of decay between the controls and the AD patients and H.M.

Figure 4 is a simplified summary plot showing only the means, averaged over trials and subjects within a given group. In summary, the data for H.M. and the AD patients revealed MEs of size and duration indistinguishable from the control subjects.

In the cases of H.M. and AD Patient 1, the dissociation between a normal ME and abnormal memory was
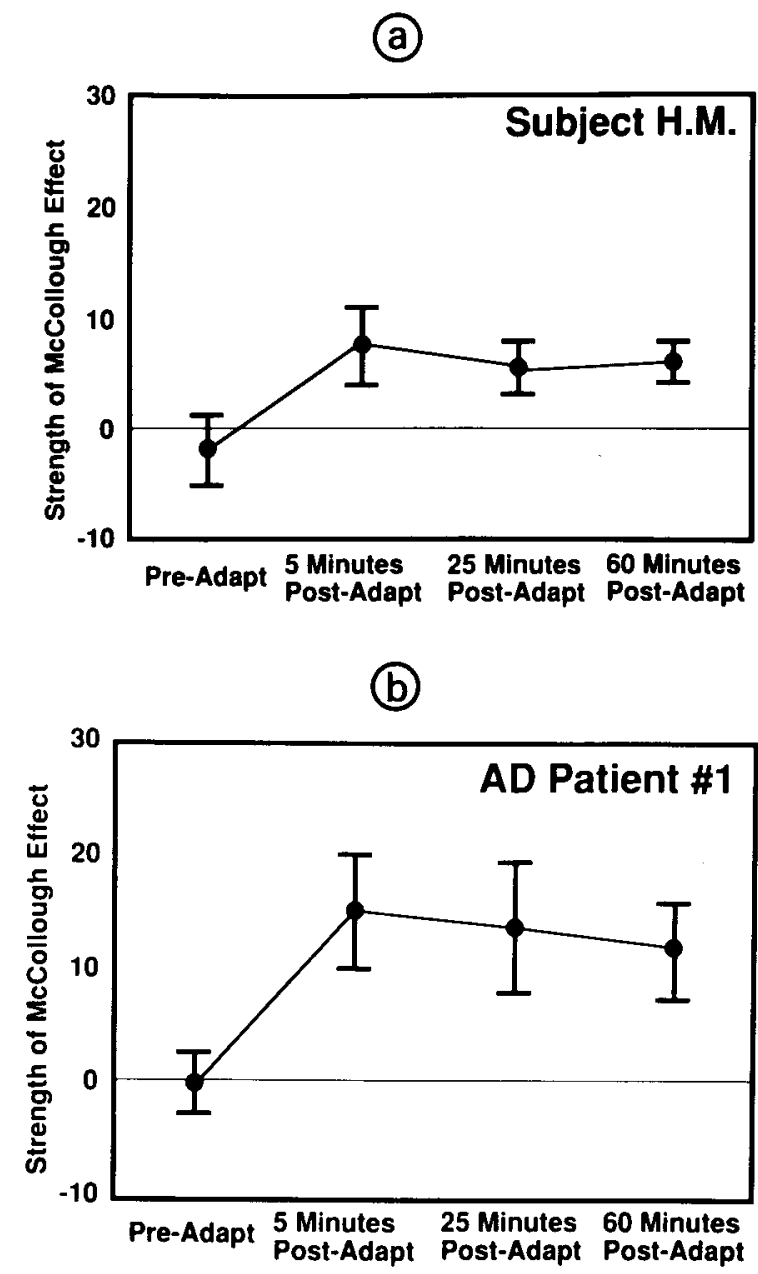

Figure 2. Individual data: The means \pm 1 standard deviation of the "neutral" settings made by the subjects. Testing times are indicated on the abscissa, although the axis itself is not quantitative. The ordinate is a measure of ME strength; specifically, it is the distance, in $L, u^{*}, v^{*}$ uniform color space, between the colors of the differently oriented bars in the test pottern. (a) Data for patient H.M. The variability is average for a good subject, as is the strength of the effect. The ME is clearly present and weakens slowly with time. (b) Data for AD Patient 1. This subject had a somewhat langer ME than average, although it was well within the normal range of $\mathrm{ME}$ strengths. The variability within this subject's data is typical for a good subject. Again, the ME is clearly present and weakens slowly with time.

particularly clear and striking. It was clear because these two were excellent psychophysical subjects in the sense that their neutral color settings were consistent. It was striking because, at the 25 -min and 60 -min postadaptation tests, neither subject could recall having seen the equipment or the adapting patterns, nor could they guess (or select from a group of colors and patterns) those that they had seen during adaptation. Nevertheless, their quantitative neutral settings revealed the ME, and the subjects also verbally reported seeing the appropriate colors when presented with objectively neutral test patterns. 


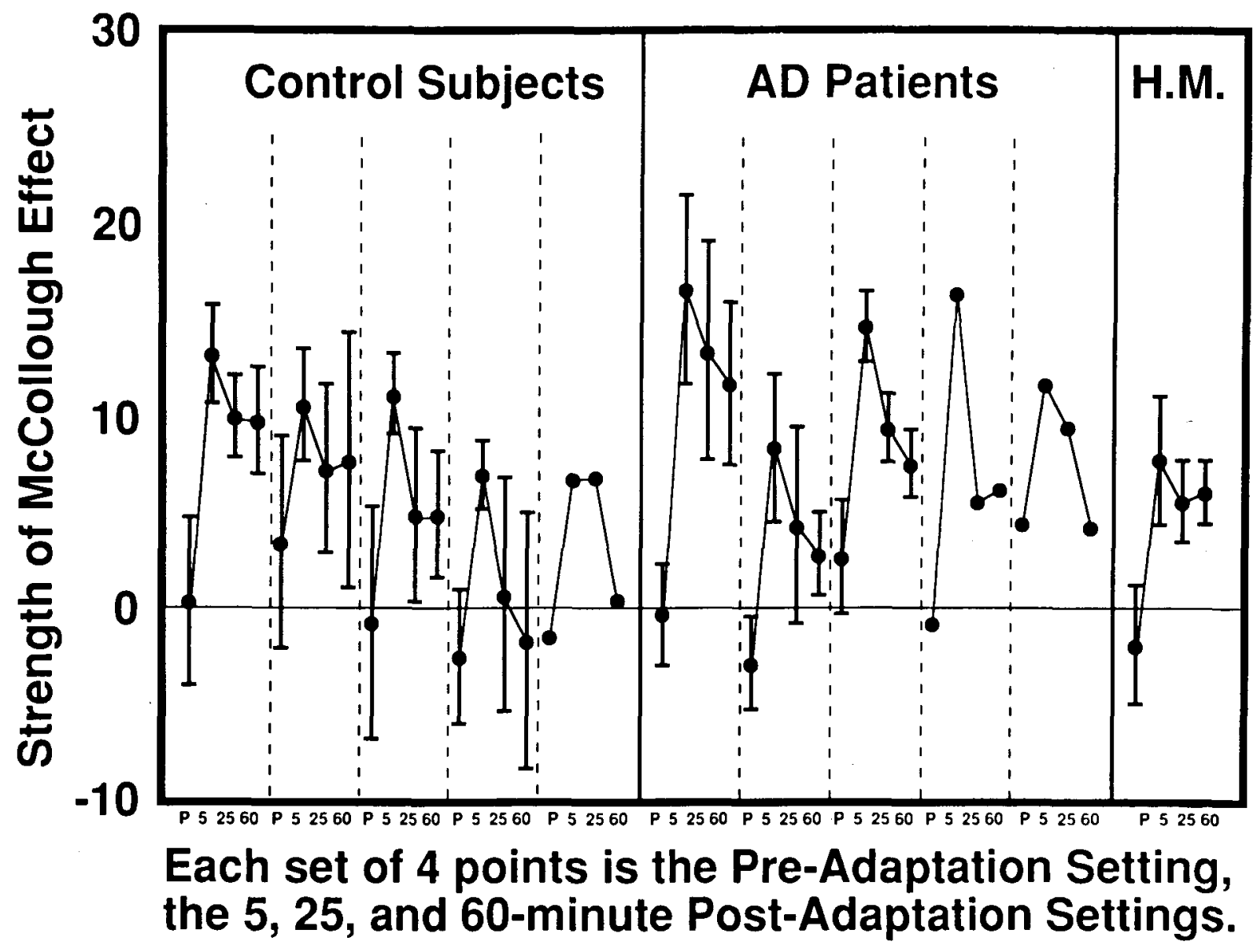

Figure 3. Individual data; all subjects: The means \pm 1 standard deviation of $M E$ strengths for each subject at preadaptation and 5 , 25 , and 60 min postadaptation. The purpose of this figure is to indicate the intersubject variability. The intersubject strength and intrasubject variability of $\mathrm{ME}$ settings is substantial. However, as is indicated in the averaged data in Figure 4 , the conclusions to be drawn in the present experiment are clear.

\section{DISCUSSION}

H.M.'s intact aftereffect demonstrates that the ME can be preserved despite global amnesia and the inability to recall or recognize any aspects of the adaptation procedure. This result was to be expected on both clinical and neural bases. From a clinical perspective, amnesic patients have shown a normal tactual aftereffect 20-25 min after adaptation (Benzing \& Squire, 1989). There is also an unpublished report on a single $\mathrm{AD}$ patient and a single Korsakoff's patient (K. White, personal communication, October 24, 1990, regarding work performed in 1977), who both showed clear MEs $5 \mathrm{~min}$ and $30 \mathrm{~min}$ after adaptation. The AD patient in that report showed no measurable ME after $90 \mathrm{~min}$, but he was reported to have had some difficulty following the standard instructions and, unlike in the present study, no special attempts were made to modify the procedure for the $\mathrm{AD}$ patient's cognitive difficulties. Weiskrantz and Warrington (1979) also reported, anecdotally, that other kinds of amnesic patients (with amnesias caused by encephalitis or Korsakoff's syndrome) demonstrated an ME. Their study, however, did not compare the ME exhibited by the amnesic patients to that of normal subjects. The present study shows that the ME may be fully normal despite global amnesia and extends the possible duration of intact perceptual aftereffects to at least $1 \mathrm{~h}$.

H.M.'s intact ME was also to be expected given the putative neural basis of the ME, as suggested by psychophysical evidence and knowledge of likely brain locus of early visual processes. There is substantial psychophysical evidence that the ME occurs relatively early in visual processing. The ME is limited to the portion of the visual field where the adapting patterns are presented; the effect does not transfer interocularly; and White, Petry, Riggs, and Miller (1978) showed that the site of binocular rivalry suppression comes subsequent to the site of the ME. Combining these facts with the well-known orientation and spatial-frequency specificities of the ME suggests a locus that includes structures as central as visual 


\section{Combined Data for All Subjects}

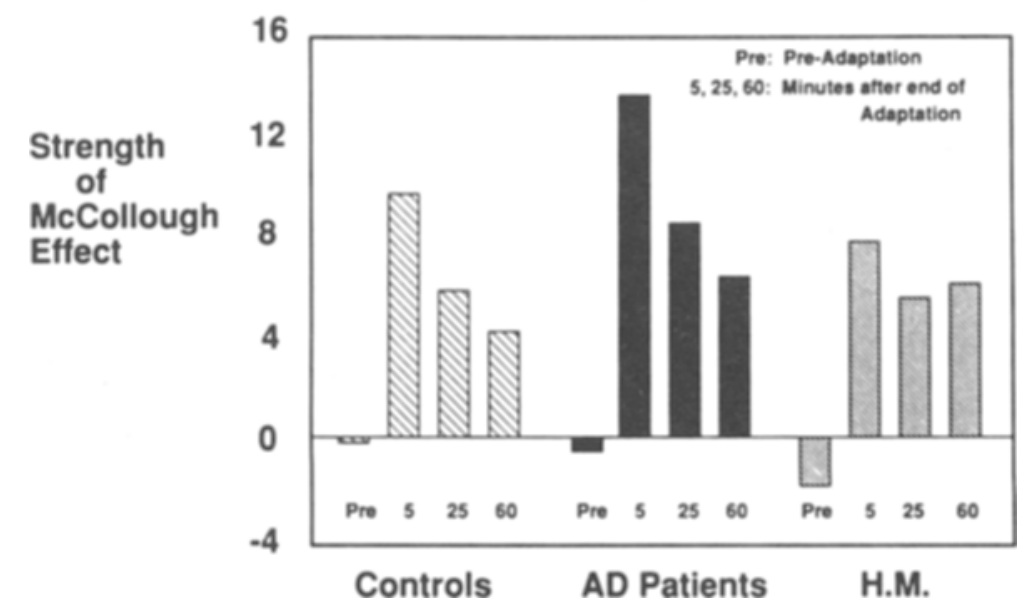

Figure 4. Summary plot: Mean ME strength, averaging over subjects within groups. H.M. and the AD patients have MEs of size and duration indistinguishable from those of the control subjects.

area $\mathrm{V} 1$, but may not require any other, more central, structures. Indeed, H.M.'s intact ME rules out contributions from the hippocampus and amygdala to the ME.

Our expectations with respect to the impact of $A D$ on the $\mathrm{ME}$ were less clear-cut. On the one hand, the preservation of the ME in H.M. suggested that limbic-system neuropathology in $\mathrm{AD}$ may not prevent $\mathrm{AD}$ patients from exhibiting an intact ME. On the other hand, AD patients have neuropathologies that extend far beyond the limbic system. Therefore, it was possible that damage to other areas in $\mathrm{AD}$ patients could lead to a marked decrease in the ME.

The anatomical changes that are the hallmark of $A D$ (namely, neurofibrillary tangles and neuritic plaques) can be found throughout the neocortex in advanced cases. Despite the general pervasiveness of $\mathrm{AD}$ in the brain, the areas that are attacked are not uniformly distributed. In vivo metabolic studies with $\mathrm{AD}$ patients report mild decreases of activity (on the order of $10 \%$ versus control subjects) in the occipital cortex and much greater decreases in the two major pathways of visual information via the temporal and parietal lobes (where decreases are more than 20\%) (see, e.g., Frackowiak et al., 1981; Johnson et al., 1988). A postmortem study showed that the number of neurofibrillary tangles was very low in area V1, 20 times more numerous in adjacent $\mathrm{V} 2$, and 40 times more numerous in the inferior temporal gyrus (Lewis et al., 1987). By the time of autopsy, there can even be damage to the optic nerve and retina in $\mathrm{AD}$ patients, although it is not the same form of damage (i.e., no plaques and tangles) seen elsewhere in the brain (Hinton, Sadun, Blanks, \& Miller, 1986). It is difficult to relate the postmortem and in vivo metabolic studies to one another and impossible to relate them directly to the pa- tients in the present study, but is it clear that the earlier a visual process occurs, the more likely it is to be preserved in $A D .^{2}$ The preservation of the $M E$ in $A D$ patients suggests that neural structures beyond $V 1$ are probably not required for generating the effect.

More specifically, the anatomical characteristics of $A D$ cited above differ in their severity in various portions of the visual cortex. Area Vl is relatively spared compared with area V2 and also compared with other more central cortical areas such as the hippocampus and neocortex (Lewis et al., 1987). It was possible, therefore, that an abnormality in ME strength or duration might be present in AD patients because of damage in these visual areas, especially area V2. Conversely, the presence of a normal $M E$ in $A D$ patients is evidence of the underlying mechanism being confined to area V1 and/or earlier visual processes. Since the orientation specificity of the ME is clearly established, and since cells showing orientation specificity do not appear in primates until area V1, the evidence seems to implicate that area as necessary for the ME. (Of course, the preceding discussion is speculative in that it assumes that the particular AD patients we dealt with had substantially more damage to area V2 and higher areas than to area V1-something that we could know with certainty only with direct anatomical examination of the brains.) As indicated in the following discussion, area V1 or other areas may supply the cells needed for the color component of the effect.

Because of its long duration and the fact that eliciting the color aftereffect is contingent on a specific test pattern, some researchers have proposed that the ME is a form of learning and memory. The most common assertion by this group of theorists is that the ME constitutes a form of classical conditioning (Murch, 1976) whereby 
the adapting patterns (for instance, a bright-green squarewave grating on a black background) represent a kind of "paired" presentation of form and color; this leads to the creation of a connection between the form and the color such that subsequent presentation of the form alone (a black-and-white grating) elicits a (negative) color response. Other theorists have argued that the ME is not a case of classical conditioning (Skowbo, 1984) but may be an example of a more primitive form of contiguity learning.

One such model of the ME (Savoy, 1984a, 1984b) speculates that the effect is due to a change in connection strengths between the inhibitory interneurons connecting the orientation-specific, spatial-frequency achromatic (broadband, with respect to wavelength) cells of area V1 with color-selective cells that are relatively insensitive to spatial orientation or spatial frequency, such as the colorselective cells of the lateral geniculate nucleus or the "blob" cells of area V1 (Livingstone \& Hubel, 1984). If this speculation is accurate, then the ME is mediated by neural systems that process visual information before that information flows to higher level visual areas, and from there to the hippocampus and other limbic areas that play a critical role in memory. Thus, the psychophysical, electrophysiological, and now, neuropsychological evidence is consistent with the physiological site of the ME being area V1. (Monocularly driven, color-specific cells are found in V1, so it may well be that the entire effect is generated in V1. Presently available data, however, do not rule out the possibility that the color component of the effect is generated in more peripheral structures, such as the lateral geniculate nucleus.) On this basis, H.M. was expected to have a normal ME despite his profound and pervasive global amnesia and, indeed, he did.

The preceding discussion glosses over the relation of "'memory," per se, to the ME. This, we believe, is a good thing. "Memory" is much too amorphous a term in the present context. It is clear that there are many types of long-term change that occur in the nervous system, and the ME is a particularly simple and relatively localized long-term change. Whether such changes are called memory or learning is a matter of semantics, not content. The key issue is the mechanism underlying the effect, and we believe the present work helps supply a pointer to its critical neural substrate.

\section{SUMMARY}

1. The McCollough effect (ME) is a long-lasting, patternspecific color aftereffect in human vision.

2. H.M., a patient with global amnesia, and 5 patients with Alzheimer's disease (AD) demonstrated an ME that was comparable to that of 5 control subjects in terms of magnitude and duration (at 5-, 25-, and 60-min delays).

3 . These results are consistent with the hypothesis that the ME is mediated in relatively early stages of visual processing.

4. Combined with recent anatomical reports of the distribution of neurofibrillary tangles and neuritic plaques in the visual cortical areas of $\mathrm{AD}$ patients at autopsy, these results point to area V1 as being a critical component of the mechanism underlying the ME.

\section{REFERENCES}

AdAms, R. D., \& Victor, M. (1985). Principles of neurology (3rd ed.). New York: McGraw-Hill.

Benzing, W. C., SQuire, L. R. (1989). Preserved learning and memory in amnesia: Intact adaptation-level effects and learning of stereoscopic depth. Behavioral Neuroscience, 103, 538-547.

BRun, A., \& Englund, E. (1981). Regional pattern of degeneration in Alzheimer's disease: Neuronal loss and histopathological grading. Journal of Histopathology, 5, 549-564.

Cohen, N. J., SQuire, L. R. (1980). Preserved learning and retention of pattern-analyzing skill in amnesia: Dissociation of knowing how and knowing that. Science, 210, 207-210.

CoRkIN, S. (1968). Acquisition of motor skill after bilateral medial temporal-lobe excision. Neuropsychologia, 6, 255-265.

CORKIN, S. (1982). Some relationships between global amnesias and the memory impairments in Alzheimer's disease. In S. Corkin, K. L. Davis, J. H. Growdon, \& E. Usdin (Eds.), Alzheimer's disease: A report of progress in research. New York: Raven Press.

CoRKIN, S. (1984). Lasting consequences of bilateral medial temporal lobectomy: Clinical course and experimental findings in H.M. Seminars in Neurology, 4, 249-259.

Eslinger, P. J., \& Damasio, A. R. (1986). Preserved motor learning in Alzheimer's disease: Implications for anatomy and behavior. Joumal of Neuroscience, 6, 3006-3009.

Frackowiak, R. S. J., Pozzillu, D., LegG, N. J., Du Boulay, G. H., MARShall, J., LenzI, G. L., \& Jones, T. (1981). Regional cerebral oxygen supply and utilization in dementia. Brain, 104, 753-778.

GABRIELI, J. D. E. (in press). Differential effects of aging and age-related neurological diseases on memory subsystems of the human brain. In F. Boller \& J. Grafman (Eds.), Handbook of neuropsychology. Amsterdam: Elsevier/North-Holland.

Gabrieli, J. D. E., Keane, M. M., Stanger, B. Z., Kuelgaard, K. S., Corkin, S., \& Growdon, J. H. (1991). Dissociations among perceptual-structural, lexical-semantic, and event-fact memory systems in global amnesic, Alzheimer's, and normal subjects. Manuscript submitted for publication.

Graf, P., Schacter, D. L. (1985). Implicit and explicit memory for new associations in normal and amnesic subjects. Journal of Experimental Psychology: Learning, Memory, \& Cognition, 11, 501-518.

HARRIS, C. S., \& GiBSON, A. R. (1968). Is orientation-specific color adaptation in human vision due to edge detectors, afterimages, or "dipoles"'? Science, 142, 1506-1507.

Heindel, W., Salmon, D., \& Butters, N. (1989). Pictorial priming and weight biasing in dementia. Society for Neuroscience Abstracts, $15,343$.

Hinton, D. R., Sadun, A. A., Blanks, C. C., \& Miller, C. A. (1986). Optic-nerve degeneration in Alzheimer's disease. New England Journal of Medicine, 142, 485-487.

Hyman, B. T., Van Hoesen, G. W., Damasio, A. R., de Barnes, C. L. (1984). Alzheimer's disease: Cell specific pathology isolates the hippocampal formation. Science, 225, 1168-1170.

Johnson, K. A., Holman, B. L., Mueller, S. P., Rosen, T. J., ENGLISH, R., NAGEL, J. S., \& Growdon, J. H. (1988). Single photon emission computed tomography in Alzheimer's disease. Archives of Neurology, 45, 392-396.

JONES, P. D., Holding, D. H. (1975). Extremely long-lasting persistence of the McCollough effect. Journal of Experimental Psychology, 1, 323-327.

KhaChaturian, Z. (1985). Diagnosis of Alzheimer's disease. Archives of Neurology, 42, 1097-1105.

Keane, M. M., Gabriel, J. D. E., Fennema, A. C., Growdon, J. H., \& CorkIN, S. (1991). Evidence for a dissociation between perceptual and conceptual priming in Alzheimer's disease. Behavioral Neuroscience, 105, 104-120. 
Krüger, J. (1979). McCollough effect: A theory based on the anatomy of the lateral geniculate body. Perception \& Psychophysics, 25, 169-179.

Lewis, D. A., Campeell, M. J., Terry, R. D., \& Morrison, J. H. (1987). Laminar and regional distributions of neurofibrillary tangles and neuritic plaques in Alzheimer's disease: A quantitative study of visual and auditory cortices. Journal of Neuroscience, 7, 1799-1808.

Livingstone, M., \& HUBEL, D. (1984). Anatomy and physiology of a color system in the primate visual cortex. Journal of Neuroscience, 4, 309-356.

McCollough, C. (1965). Color adaptation of edge-detectors in the human visual system. Science, 149, 1115-1116.

McKahn, G., Drachman, D., Folstern, M., Katzman, R., Price, D., \& Stadlan, E. (1984). Clinical diagnosis of Alzheimer's disease: Report of the NINCDS-ADRDA work group under the auspices of Department of Health and Human Services task force on Alzheimer's disease. Neurology, 34, 939-944.

MiChaEL, C. R. (1978). Color vision mechanisms in monkey striate cortex: Simple cells with dual opponent-color receptive fields. Journal of Neurophysiology, 41, 1233-1249.

Montalvo, F. S. (1976). A neural network model of the McCollough effect. Biological Cybernetics, 25, 49-56.

Murch, G. M. (1976). Classical conditioning of the McCollough effect: Temporal parameters. Vision Research, 16, 615-619.

Peterhans, E., \& von der Heydt, R. (1989). Mechanisms of contour perception in monkey visual cortex. II. Counters bridging gaps. Journal of Neuroscience, 9, 1749-1763.

Posner, M. I., Petersen, S. E., Fox, P. T., \& Raichle, M. E. (1988). Localization of cognitive operation in the human brain. Science, $\mathbf{2 4 0}$, 1627-1631.

SAvoY, R. L. (1984a). "Extinction"” of the McCollough effect does not transfer interocularly. Perception \& Psychophysics, 36, 571-576.

SAvoY, R. L. (1984b). Modeling the McCollough effect. Investigative Ophthalmology \& Visual Science, Supplement, 25, 234.

SAvoY, R. L. (1986). Making quantized images appear smooth: Tricks of the trade in vision research. Behavior Research Methods, Instruments, \& Computers, 18, 507-517.

SCoville, W. B., Dunsmore, R. H., Liberson, W. T., Henry, C. E., \& PEPE, A. (1953). Observations on medial temporal lobectomy and uncotomy in the treatment of psychotic states. In Proceedings of the Association for Research in Nervous and Mental Disease (pp. 347369). Baltimore: Williams and Williams.

SCOVILLE, W. B., \& MiLNer, B. (1957). Loss of recent memory after bilateral hippocampal lesions. Journal of Neurology, Neurosurgery, \& Psychiatry, 20, 11-21.

Sкошво, D. (1984). Are McCollough effects conditioned responses? Psychological Bulletin, 96, 215-226.

Skowbo, D., Timney, B. N., Gentry, T. A., Morant, R. B. (1975). McCollough effects: Experimental findings and theoretical accounts. Psychological Bulletin, 82, 497-510.

Solomon, P. R., LeVine, E., Bein, T., \&endebury, W. W. (1989).
Disrupted classical eyeblink conditioning in patients with Alzheimer's disease. Society for Neuroscience Abstracts, 15, 888.

Squire, L. R. (1986). Mechanisms of memory. Science, 232, 1612-1619.

StromeYer, C. F., III, \& DAwSON, B. M. (1978). Form-color aftereffects: Selectivity to local luminance contrast. Perception, 7, 407-415.

Victor, M., Adams, R. D., Colluns, G. H. (1971). The WernickeKorsakoff Syndrome. Philadelphia: Davis.

von der Heydt, R., \& Peterhans, E. (1989). Mechanisms of contour perception in monkey visual cortex. I. Lines of pattern discontinuity. Journal of Neuroscience, 9, 1731-1748.

WARRINGTON, E. K., \& JAMES, M. (1988). Visual apperceptive agnosia: A clinico-anatomical study of three cases. Cortex, 24, 13-32.

Weiskrantz, L., \& Warrington, E. K. (1979). Conditioning in amnesic patients. Neuropsychologia, 17, 187-194.

White, K. D., Petry, H. M., Riggs, L. A., \& Miller, J. (1978). Binocular interactions during establishment of McCollough effects. Vision Research, 18, 1201-1215.

Woodruff-Pak, D. S., Finkbiner, R. G., \& Katz, I. (1989). Classical conditioning of the eyelid response in normal elderly and in patients diagnosed with Alzheimer's disease. Sociery for Neuroscience Abstracts, 15, 862.

Zola-Morgan, S., Souire, L. R., * Amaral, D. (1986). Human amnesia and the medial temporal region: Enduring memory impairment following a bilateral lesion limited to the CA1 field of the hippocampus. Joumal of Neuroscience, 6, 2950-2967.

\section{NOTE}

1. "Consecutive cases" indicates that no special selection procedures were used; $A D$ patients were taken as they appeared, provided only that they met the preceding criteria (their dementia was mild-moderate and they had volunteered)

2. The idea that relatively spared visual cortices may support some aspects of visual learning in AD is supported by two recent findings of intact magnitudes for visual priming for picture and word identification in AD patients (Gabrieli et al., 1991; Keane, Gabrieli, Fennema, Growdon, \& Corkin, 1991). Evidence from positron emission tomography (PET) studies with normal subjects (Posner, Petersen, Fox, \& Raichle, 1988), neuropsychological studies (Warrington \& James, 1988), and monkey neurophysiological studies (Peterhans \& von der Heydt, 1989; von der Heydt \& Peterhans, 1989) all suggest that such priming may be mediated primarily by the extrastriate visual cortex. Although parceling of visual processing into striate and extrastriate components is not possible with AD studies, the priming results are consistent with the notion that the relatively spared occipital cortex in AD supports visual plasticity in a wide range of tasks.

(Manuscript received June 22, 1989; revision accepted for publication December 31, 1990.) 